\title{
ESPACIO DEL EDITOR
}

\section{Revista Investigación Económica: análisis bibliométrico a partir de redalyc.org, 2005-2014}

\author{
Eduardo Aguado López ${ }^{\mathrm{a}, \mathrm{b}}$ y Arianna Becerril García ${ }^{\mathrm{a}}$
}

\begin{abstract}
Resumen
A partir de un análisis bibliométrico se realiza una caracterización de la revista Investigación Económica, donde el universo de estudio lo componen sus publicaciones en redalyc. org (199 artículos científicos del periodo 2005-2014). Asimismo, se utilizan indicadores (producción, colaboración y uso, propuestos también por dicha base de datos) que corresponden a métricas alternativas y complementarias a los índices convencionales de análisis de la ciencia escrita. Se concluye que la revista constituye un referente de internacionalización y visibilidad en las ciencias económicas, dada la importante presencia de producción externa, cuyo desempeño impulsa la creciente colaboración entre investigadores y la descarga de los artículos llevada a cabo predominantemente fuera de las fronteras nacionales. Sin embargo, este esfuerzo debe traducirse en citas a la revista, donde hay una asignatura pendiente y diversas áreas de oportunidad y fortalecimiento. Palabras clave: análisis bibliométrico, Investigación Económica, ciencias económicas, colaboración, redalyc.org
\end{abstract}

Clasificación JEL: A, A1, A14.

\begin{abstract}
A characterization of the journal Investigación Económica (Economic Research) is performed as a result of a bibliometric analysis, where the universe of study is composed by its publications available in redalyc.org (199 scientific papers of the period 2005-2014). In addition, the analysis includes indicators (based on production, collaboration and usage; also proposed by that database) that conform an alternative and complementary way to analyze written science. The conclusion shows that this journal is a reference to internationalization and visibility in economics, given the strong presence of for-
\end{abstract}

a Ambos autores están adscritos a la Universidad Autónoma del Estado de México (UAEM).

b Autor para correspondencia: eal123@gmail.com. 
eign publications, whose performance drives two effects: the increased collaboration among researchers and the international papers download. However, this effort should result in citations to the journal, where there is a pending issue and diverse areas of opportunity and strengthening.

Key words: bibliometric analysis, Economic Research, Economics, collaboration, redalyc.org.

\section{INTRODUCCIÓN}

La bibliometría ha cobrado gran importancia en las últimas décadas como herramienta para el análisis de las múltiples formas en que se genera, crece y circula el conocimiento científico (De Solla, 1986, p. 136). Su importancia radica en que desde la segunda mitad del siglo xx ha dado insumos a los distintos actores que participan del ejercicio científico para establecer prospectivas de las directrices de las disciplinas, instituciones, publicaciones, autores, países y regiones geográficas específicas, en la búsqueda de un adecuado desenvolvimiento y visibilidad en sus distintos contextos.

Factores como el modelo imperante de difusión de la información científica donde se fomenta el interés en las diversas entidades científicas por incrementar su impacto, y el surgimiento de las grandes bases de datos científicos, como fuentes de información y legitimación, dieron lugar al impulso de los análisis bibliométricos, cuyo uso se encuentra ya generalizado en la "descripción, evaluación y monitoreo del ejercicio científico” (Romaní, Huamaní y González, 2011, p. 53). Destacan entre sus principales usos su papel en el diseño de políticas científicas y tecnológicas y en la evaluación al desempeño de la investigación, ejercicios que, según diversas investigaciones, han traducido en términos cuantitativos la forma más objetiva de medir el desempeño de los actores involucrados en el desarrollo científico (Moreno y Urzúa, 2015, p. 71; Horwood y Robertson, 2010, p. 1; Sánchez, Carrillo y Garrido, 2015, p. 46).

La forma en que se ha abordado usualmente la bibliometría ha sido a partir de variables de estudio en torno a la producción y circulación de la ciencia escrita, entre las que destaca el comportamiento de la cantidad de artículos publicados, idioma en que se ha publicado, número de firmas, procedencia de los autores, metodología usada, las temáticas en torno a las cuales se investiga, obsolescencia, distribución zipf y waring, la cantidad de citas que reciben los determinados artículos en un periodo dado, la cantidad y procedencia de las referencias que albergan los textos e índice de inmediatez (Marenco, 2013, pp. 25- 
31; López, Vázquez y Sarasola, 2015, pp. 65-85; Carvajal y Matamoros, 2013, pp. 1-20; Gordo, 2014, pp. 63-85; Gómez et al., 2012, pp. 17-41; Spinak, 1998, p. 145). No obstante, otros estándares de medición se han legitimado como los principales en la caracterización y análisis de la ciencia que se genera alrededor del mundo. El factor de impacto (Garfield, 2006), índice H (Hirsch, 2005) y SCImago Journal and Country Rank (SJR) (SCImago, 2007, pp. 645-646) se han instituido como las principales métricas del conocimiento científico en todas las regiones geográficas y áreas de conocimiento y, en consecuencia, han inclinado la balanza de la evaluación al análisis de dichos indicadores.

Un punto medular es que al aceptarse tales índices como los estándares en el análisis del desempeño científico, también se han implantado universos de información sobre los cuales esto se lleva a cabo, como es el caso de Scopus de Elsevier y el Journal Citation Reports (JCR) del Web of Science, bases de datos comerciales que hacen de la ciencia y del conocimiento que se genera un "mercado del conocimiento" (Zamorano, 2012, p. 6). De ello se desprende la dificultad de arribar a conclusiones completas por la limitante que implica caracterizar a la ciencia en función del universo que se utilice.

Respecto al contexto latinoamericano, un aspecto que destaca del uso de dichos indicadores y bases de datos es la subrepresentación de la ciencia regional en dichos universos de información. Muestra de ello es que en la edición de 2015 del JCR se registró la presencia de 360 revistas de Iberoamérica, las cuales estaban distribuidas entre la Península Ibérica, con el 34.4\% de las publicaciones, y Brasil, con el 32.5\%; mientras que el resto de países latinoamericanos representaron el 33.1\%. Por su parte, en el mismo año, Scopus a través del sJR registraba 1226 revistas distribuidas entre la Península Ibérica con el 40.7\%, Brasil con el 27.3\% y la región latinoamericana restante con el 32.0\%. El panorama que se muestra es un mapa que no representa el territorio real de la ciencia escrita iberoamericana, sino apenas dos regiones (Península Ibérica y Brasil) que tienen más cabida en los estándares exigidos por dichas bases de datos. A esto se suma la poca presencia de revistas enfocadas a las ciencias sociales, donde el JCR muestra una subrepresentación mayor: en el mismo año, las publicaciones de esta área participaron únicamente con el 29.4\%. Por su parte el sjR concentra el $42.2 \%$ de revistas en la misma área de conocimiento.

El uso de métricas y universos de información incompletos ha traído consigo que se evalúe a la región en los mismos términos en que se hace para el caso de la ciencia anglosajona, cuyo contexto y agenda de investigación son ajenos 
a los de Latinoamérica, teniendo de esa forma resultados desventajosos para esta región, por debajo de la media que marca la ciencia de "corriente principal” (Morales y Aguado, 2010, p. 161). Tal aspecto se aprecia con claridad si se analiza el desempeño de Investigación Económica (IE) bajo estos indicadores y en dichas bases de datos.

IE ingresa al JCR en 2008, año desde el cual se ha mantenido en el cuartil 4, al igual que las otras dos revistas mexicanas de economía indizadas en dicha base: Trimestre Económico (Fondo de Cultura Económica, FCE) y Economía Mexicana Nueva Época (Centro de Investigación y Docencia Económicas, CIDE), que cambió de nombre en 2014 a Latin American Economic Review (LAER). ${ }^{1}$ Asimismo, en el universo del JCR, integrado por 333 revistas (edición 2015), IE ocupa la posición 322. Si se hace una razón 322/333 resulta el lugar en el que está IE en una escala del 0 al 1, aunque el universo varíe, donde su posición sería: 2014: 0.97; 2013: 0.96; 2012: 0.97; 2011: 0.91; 2010:0 .98; 2009: 0.96; y 2008: 0.99. Es decir, para pasar al cuartil 3, IE tendría que superar el factor de impacto (FI) de alrededor de 80 revistas o, dicho de otra forma, mejorar alrededor de 80 posiciones. La posición de las otras dos revistas mexicanas de economía en el JCR es similar: en 2014 Trimestre Económico obtiene 0.97 y Economía Mexicana Nueva Época 0.98 , la cual no tuvo tiempo suficiente para poder obtener un FI, aunque destaca que en el mismo año obtuvo una cita, mientras Economía Mexicana Nueva Época recibía alrededor de 15 al año. La pregunta es si cambiar de nombre (perder su historia), usar servicios editoriales comerciales de Springer, aceptar trabajos exclusivamente en inglés, o desear convertirse en el referente de la discusión económica de Latinoamérica, permaneciendo en acceso abierto (el sitio web dice que el CIDE patrocina el costo de los trabajos sometidos). Con cambiar de nombre, como dice el Editor en Jefe Juan Rosellon, "básicamente lo que estamos buscando es incrementar el factor de impacto y la calidad de los artículos". 2 El tiempo lo dirá con claridad.

1 Es importante mencionar que Economía Mexicana al cambiar su nombre a Latin American Economic Review (LAER) aparece en SJR y Scopus como de Berlín, lo que no responde a un error del sistema, sino a un conflicto de autoría y propiedad del Número Internacional Normalizado de Publicaciones Seriadas (ISSN, International Standard Serial Number). Asimismo, resulta curioso que en la página de SpringerOpen se manifiesta que el CIDE patrocina la publicación y no que la revista, propiedad del CIDE, ha decidido trabajar bajo un esquema de acceso abierto y no cobrar a los autores por ello.

2 Véase CIDE, 2013. Juan Rosellón nos habla de la revista "Latin American Economic Review - LAER". [video en línea] Disponible en: <https://www.youtube.com/watch?v=IpGHV_JO30w>. 
Por su parte, en Scopus, a través del sjR (edición 2015), en el área de Economía, Econometría y Finanzas se ubicaron cuatro revistas mexicanas, incluida IE, la cual ocupa el cuartil 3, posición que logró mantener en 2013 y 2014. Latin American Economic Review ocupa en esta base de datos el cuartil 4; Problemas de Desarrollo (Instituto de Investigaciones Económicas de la Universidad Nacional Autónoma de México, IIEc-UnAm) el cuartil 4 y América Latina en la Historia Económica (Instituto de Investigaciones Dr. José María Luis Mora) el cuartil 3.

Si el análisis de IE se hace exclusivamente bajo el impacto de la bases abordadas, nuestra percepción de las revistas sería probablemente negativa, a pesar de que son éstas las únicas revistas mexicanas del área de economía que han podido acceder al selecto grupo de la llamada ciencia de corriente principal. Ante esto es que redalyc.org propone un conjunto de indicadores bibliométricos alternativos y complementarios a los índices convencionales, en el análisis de la ciencia iberoamericana. Al proponer métricas distintas (indicadores de producción, colaboración y uso), se propone también un universo regional de estudio, integrado por revistas de Iberoamérica, latinoamericanas y de ciencias sociales principalmente; con el fin de mirar de forma distinta y más objetiva al quehacer científico regional, desde un esquema más apropiado, dejando de lado el paradigma de los “ojos prestados" (Spinak, 1996, p. 145).

En el cometido de construir un espacio de comunicación entre especialistas y de visibilización del conocimiento en las ciencias económicas, IE llega a su aniversario 75, evento que se conmemora con un análisis del papel que ha fungido en los últimos años alrededor del debate científico y económico contemporáneo, mostrando una caracterización a partir de los actores involucrados y los patrones que se han seguido en términos de producción y colaboración, al tiempo que analiza la presencia de la revista entre los especialistas en economía desde sus indicadores de uso.

\section{MÉtodo}

Para hacer una caracterización objetiva de IE se recurre a redalyc.org, dado que ofrece indicadores acerca de las tendencias que muestran los países, instituciones, disciplinas, revistas y autores, en términos de producción, colaboración y uso de la obra, de 2005 a 2014, a través del Sistema de Información Científica Redalyc (SICR). redalyc.org ofrece un universo completo y homogéneo de estudio que no sólo posibilita los análisis necesarios para dar cuenta del 
desempeño que presenta IE, sino que constituye, en general, una herramienta provechosa para el análisis de la producción científica que se publica en revistas iberoamericanas de libre acceso, área de estudio en la que las bases de datos no padronizadas e incompletas resultan una constante que obstaculiza tal enmienda, como plantean Café y Bräscher (2008, p. 67) y De Filippo y Fernández (2001, p. 3).

La base de datos de la cual se desprende el universo de estudio está integrada por un total de 297050 textos académicos a texto completo, compuestos por 269226 artículos científicos, 6290 editoriales, 13376 reseñas y 8158 textos de diversa índole. Participando en todo ello 165 países, 21346 instituciones, 1017 revistas, 17 países editores y 517 instituciones editoras. Por su parte, en el acervo de IE, de 2005 a 2014, se registran 213 trabajos académicos a texto completo que se desprenden de 45 fascículos, un promedio de 5.4 artículos por número y 21 artículos por año. A su vez, de tal conjunto se extrajeron cuatro editoriales, tres reseñas y siete textos de diversa índole; resultando así una base compuesta por 199 artículos científicos, donde se registra la participación de 301 autores con adscripción a 150 instituciones de 33 países, lo cual constituye el universo de información sobre el cual se realizó el análisis de IE (véase el cuadro 1).

\section{Cuadro 1}

Universo fuente y universo de estudio, 2005-2014

\begin{tabular}{lrc}
\hline & Redalyc & Investigación Económica \\
\hline Artículos & 269226 & 199 \\
Artículos en colaboración & 181486 & 111 \\
Artículos de autoría & 87740 & 88 \\
Instituciones & 21346 & 150 \\
Países & 165 & 33 \\
Disciplinas & 38 & 1 \\
Revistas & 1017 & 1 \\
Editoriales & 6290 & 4 \\
Reseñas & 13376 & 3 \\
Otros textos & 8158 & 7 \\
Producción por países & 289380 & 232 \\
Producción por instituciones & 388439 & 278 \\
\hline
\end{tabular}

Fuente: Sistema de Información Científica Redalyc (SICR) de la UAEM. Disponible en: $<\mathrm{http}: / / \mathrm{www} \cdot$ redalyc.org $>$. 
Asimismo, para contextualizar las tendencias que sigue IE en su indicador de producción, se le contrasta con el total de revistas que integran el área de Economía y Finanzas de redalyc.org, comparándolas en función de su producción externa, interna institucional e interna no institucional. Así, la sección "Tendencias de producción" se divide en dos apartados: en el primero se aprecia a IE en el contexto de dichas revistas, mientras que en el segundo se le observa desde las tendencias que muestra en lo particular.

\section{Resultados}

\section{Tendencias de producción}

I. IE en el contexto internacional. En el análisis de las revistas científicas se parte usualmente del entendido de que una revista es un órgano de comunicación académica y científica de corte internacional, regional, nacional o local, vista desde las problemáticas que analiza. Sin embargo, mientras más amplia y diversa sea institucional y geográficamente la comunidad que en éstas publica, podrá corroborarse que una revista es un órgano de comunicación global, razón por la que no debe haber restricción — lo cual es importante enfatizar- para que los investigadores participen en ella. En el análisis de una revista bajo este eje de argumentación, la producción externa constituye el sustento analítico; específicamente, el porcentaje de publicación externa sobre el número total de artículos.

En la gráfica que se expone a continuación se observa la composición de la producción de las cerca de 50 revistas del área de Economía y Finanzas indizadas en redalyc.org, incluida IE, en un promedio de 10 años (2005-2014) o desde que apareció el primer número de la revista. Con la finalidad de observar el peso de la producción externa contrastando su presencia con la producción nacional y con otras publicaciones, se aprecia la composición general de la producción, donde se inscribe la producción externa, la producción interna institucional (PII), que son los artículos de autores adscritos a una misma institución mexicana y la interna no institucional (PINI), que son los artículos de autores adscritos a distintas instituciones mexicanas. Resalta que en principio podría decirse que una revista internacional debería superar el 50.0\% de las publicaciones externas y tener una proporción equilibrada al interior, es decir, $25.0 \%$ interna no institucional y $25.0 \%$ interna institucional. 


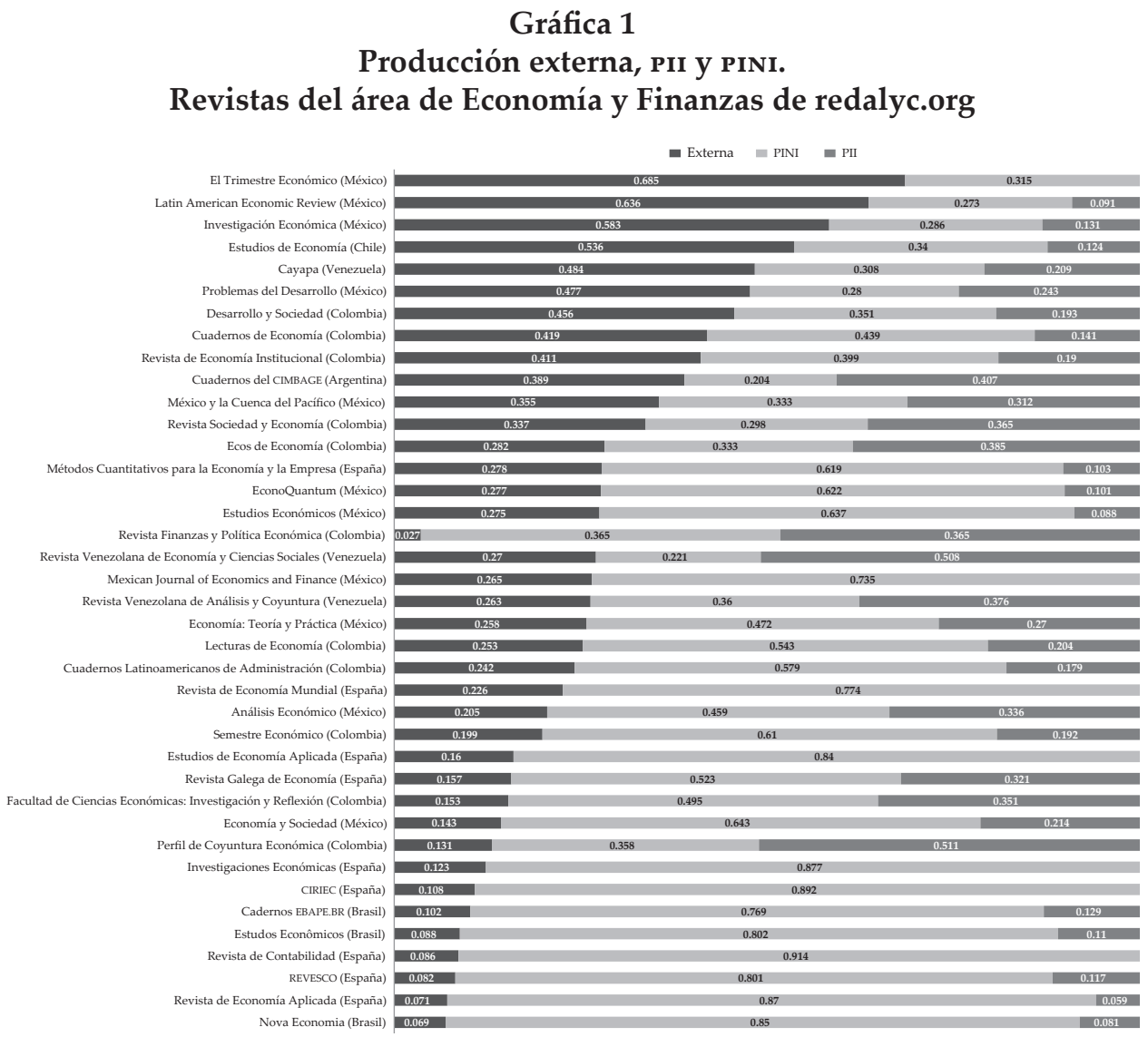

Fuente: SICR, UAEM. Disponible en: <http://www.redalyc.org>.

Como se observa en la gráfica 1, sólo en cuatro revistas se cumple lo dicho anteriormente: Trimestre Económico (68.5\%), Latin American Economic Review (63.6\%) e Investigación Económica (58.3\%), todas éstas de México, y Estudios de Economía de Chile con 53.6\%. En ninguna de éstas se supera el 14.0\% de producción institucional, por lo que podrían ser identificadas, bajo este análisis, como revistas internacionales consolidadas. En el sexto lugar está Problemas del Desarrollo con $47.7 \%$ de producción externa, $28.0 \%$ nacional no institucional y $24.3 \%$ institucional, que bajo este enfoque podría ser definida como una revista internacional en transición a la consolidación.

De tal forma, como órgano global con temáticas circunscritas conceptual y regionalmente, se analiza la forma en que IE se ha ido constituyendo en un 
referente en las ciencias económicas, en la medida en que participa en una red global de debate, al cual adscribe a todos sus autores sin importar el espacio geográfico de éstos. Así, una revista que logra convertirse en punto de referencia en su área (razón por la cual es importante una clara temática de una revista contra el impulso en Latinoamérica de coberturas generalistas) es aquella donde los autores que escriben y estudian esa temática: a) la conocen, b) someten sus trabajos e investigaciones para publicación, c) la leen para conocer lo que plantean los colegas con preocupaciones analíticas afines y d) la utilizan como referencia en sus investigaciones, sus clases, etcétera.

Es importante destacar que la producción externa se compone a su vez por tres variables: autores extranjeros que publican individualmente (A), autores extranjeros que mantienen coautoría con otros extranjeros (B) y autores extranjeros que mantienen coautoría con investigadores nacionales $(C)$. En el caso de IE, el componente de producción externa que tiene mayor incidencia es el tipo B, con 71 casos; seguido del componente A, con 48 casos, y del C, con 16 casos (véase el cuadro 2). Resalta de tal forma que si bien la producción externa tiene un buen desempeño en IE, tanto por su crecimiento como por su gran peso relativo, su presencia está siendo impulsada principalmente por la colaboración entre autores extranjeros, quedando al descubierto que la colaboración de investigadores extranjeros con nacionales se encuentra aún en consolidación.

\section{Cuadro 2}

Variables (componentes) de la producción externa por países que han publicado en Investigación Económica

\begin{tabular}{lrcc}
\hline \multirow{2}{*}{ País } & \multicolumn{3}{c}{ Tipo } \\
\cline { 2 - 4 } & A & B & C \\
\hline Alemania & 2 & 5 & 1 \\
Argentina & 1 & 1 & \\
Australia & 3 & & 1 \\
Austria & 5 & 14 & \\
Brasil & & 1 & \\
Canadá & 2 & 2 & 1 \\
Chile & & 1 & \\
China & 1 & 1 & 4 \\
Colombia & & 1 & \\
Corea del Sur & & 2 & \\
Ecuador & & 20 & \\
España & 7 & & \\
\hline
\end{tabular}


Cuadro 2, continuación...

\begin{tabular}{|c|c|c|c|}
\hline \multirow{2}{*}{ País } & \multicolumn{3}{|c|}{ Tipo } \\
\hline & $\mathrm{A}$ & B & $\mathrm{C}$ \\
\hline Estados Unidos & 9 & 8 & 3 \\
\hline Filipinas & & 1 & \\
\hline Francia & & & 2 \\
\hline Grecia & 1 & & \\
\hline Italia & 4 & 2 & 2 \\
\hline Japón & 1 & & \\
\hline Malasia & 1 & & \\
\hline Noruega & 1 & & \\
\hline Nueva Zelanda & & 1 & \\
\hline Perú & 4 & & \\
\hline Portugal & & 1 & \\
\hline Puerto Rico & 1 & & \\
\hline Reino Unido & 2 & 3 & 2 \\
\hline República Dominicana & 1 & & \\
\hline Rusia & & 1 & \\
\hline Suiza & 1 & & \\
\hline Trinidad y Tobago & & 1 & \\
\hline Turquía & & 1 & \\
\hline Uruguay & 1 & 1 & \\
\hline Venezuela & & 2 & \\
\hline Total & 48 & 71 & 16 \\
\hline
\end{tabular}

Fuente: SICR, UAEM. Disponible en: <http://www.redalyc.org >.

En el caso A (autores extranjeros que publican individualmente) se registran 48 interacciones de 19 países, de los cuales destacan Estados Unidos, España, Brasil e Italia, que en conjunto concentran el 52.0\% de los autores que participan en IE bajo esta modalidad (véase el cuadro 2), cuya red se muestra en el mapa 1.

El caso B, autores extranjeros que participan en colaboración con otros autores extranjeros, involucra 22 países, la red más densa de los tres casos. Destacan Brasil, Estados Unidos y España (véase el mapa 2) como los países que más han logrado establecer vínculos en torno a proyectos de investigación conjuntos, los cuales se traducen en nodos de las redes de colaboración científica actual.

Finalmente, los países que han establecido vínculos de trabajo con México son ocho, a partir de 12 interacciones. Destacan Estados Unidos y España como los países que más han colaborado con autores nacionales (véase el mapa 3). 


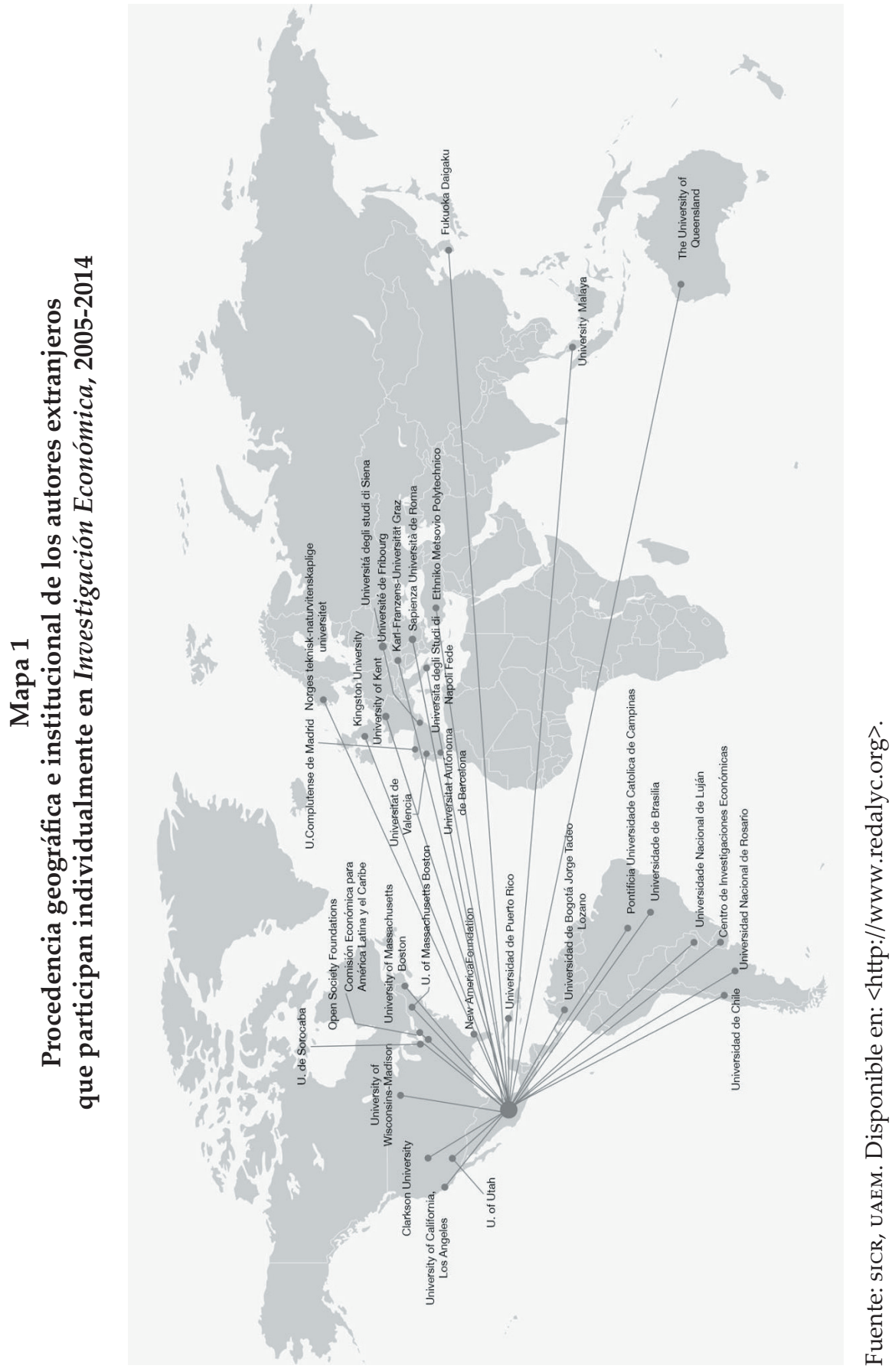



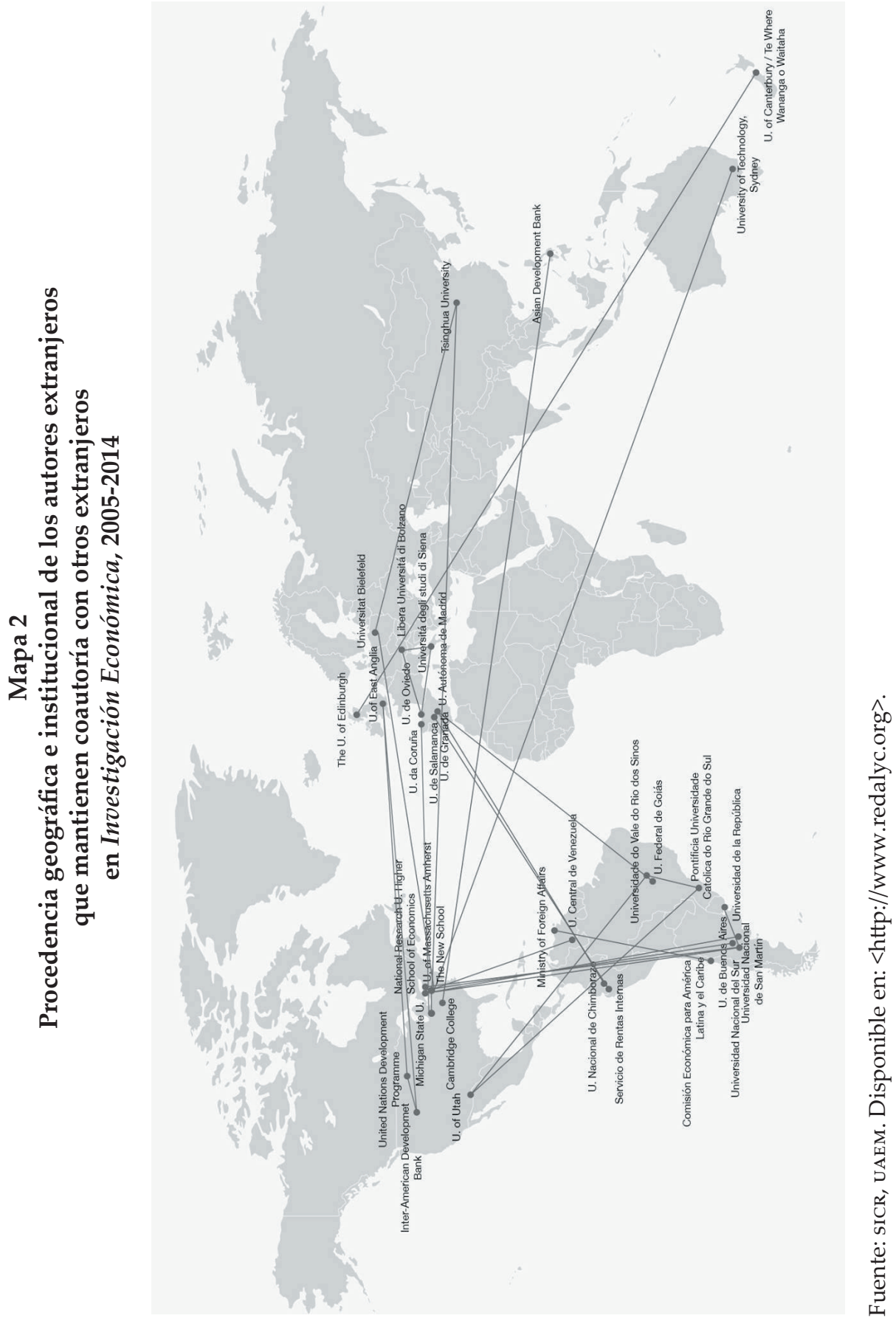

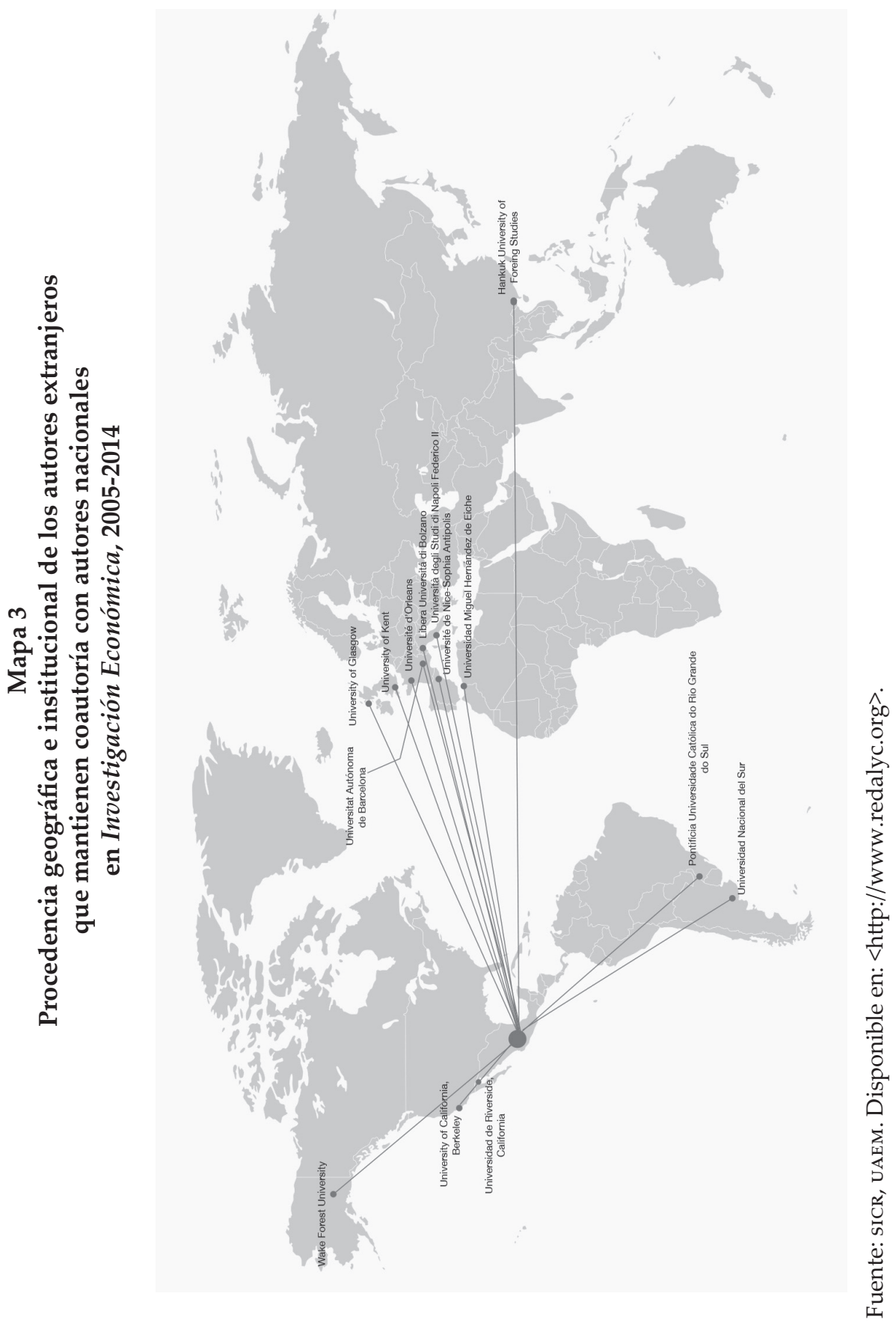
II. Tendencias al interior de IE. Se plantea como un proyecto plural, por lo cual acepta para su revisión y posible publicación productos científicos tanto nacionales como extranjeros. Busca contribuir a las ciencias económicas desde una orientación teórica heterodoxa que no se sujete a las fronteras nacionales. Por su parte, en el análisis de la producción científica que publica, se advierte una mayor presencia de la producción proveniente del extranjero, lo que es un enfoque distinto para apreciar la tendencia a la internacionalización de IE.

La producción externa tiene una tendencia a la alza: su peso relativo pasa del $57.9 \%$ en 2005 , al $75.0 \%$ en 2014 , como se observa en la gráfica 2 . A esto se agrega su tasa de crecimiento media acumulada (TCMA) de $14.1 \%$, que contrasta con el $-0.5 \%$ de la producción interna (artículos de autores adscritos a instituciones mexicanas).

\section{Gráfica 2}

Tasa de crecimiento media acumulada y distribución de la producción interna y producción externa, 2005-2014

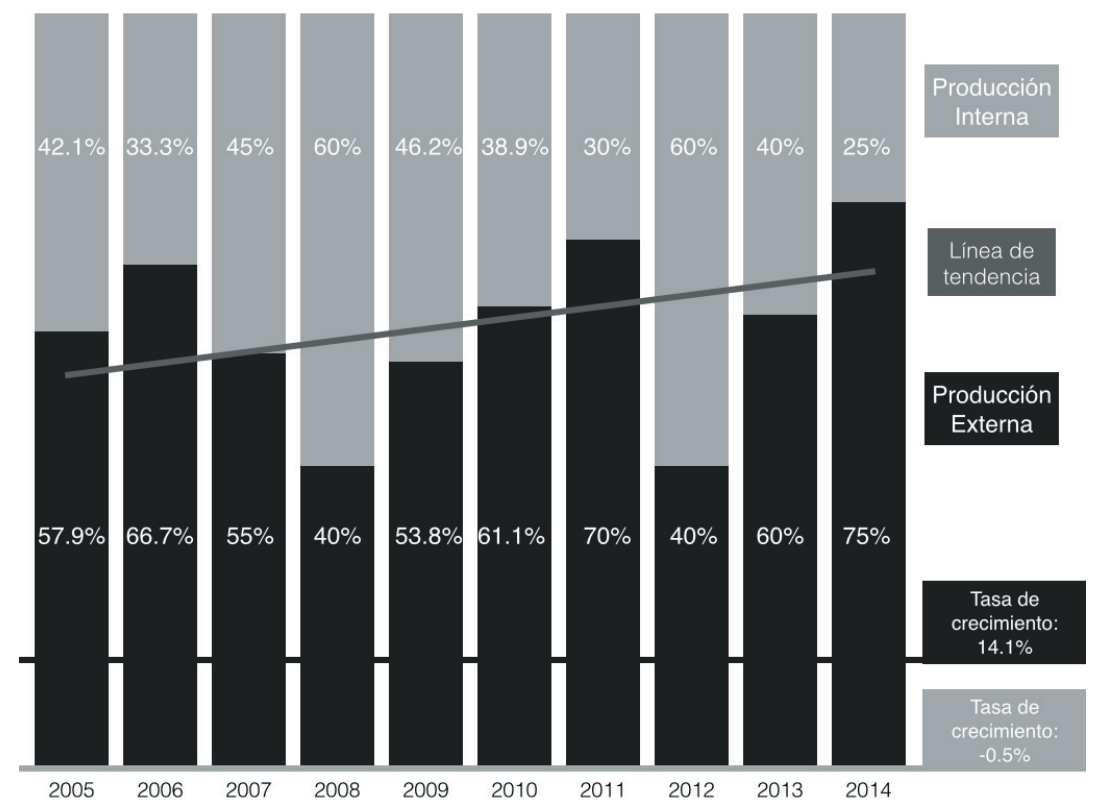

Fuente: SICR, UAEM. Disponible en: <http://www.redalyc.org $>$.

El crecimiento de la producción proveniente del extranjero pone de manifiesto el reconocimiento que ha ganado IE entre los investigadores de alrede- 
dor del mundo, quienes la consideran un canal apropiado para participar en la narrativa de las ciencias económicas. Tal reconocimiento no se circunscribe a Iberoamérica, sino que se expande a otras regiones del mundo, lo que se observa en la distribución de las regiones que más han publicado en IE, la cual es la siguiente: Latinoamérica (62.1\%), Iberoamérica (13.8\%), Europa (12.1\%), América del Norte (9.0\%), Asia $(2.6 \%)$ y Oceanía (0.4\%).

Por su parte, la producción interna institucional, si bien tiene un peso relativo adecuado al interior de la producción total de IE (13.1\%, como se señala en la gráfica 1), muestra cuatro años críticos (2007, 2009, 2010 y 2012) en que su presencia oscila entre $42.8 \%$ y $58.3 \%$ (véase la gráfica 3). Esto habla de una gran presencia de la institución editora en la producción en determinados momentos y que no refleja prácticas editoriales del todo adecuadas para una revista que busca ser un referente internacional. Se tiene pues una doble tendencia: hay una creciente aceptación de trabajos provenientes del extranjero, mientras que al interior la UNAM ha adquirido gran peso en determinados periodos.

\section{Gráfica 3}

Producción interna institucional

y producción interna no institucional, 2005-2014

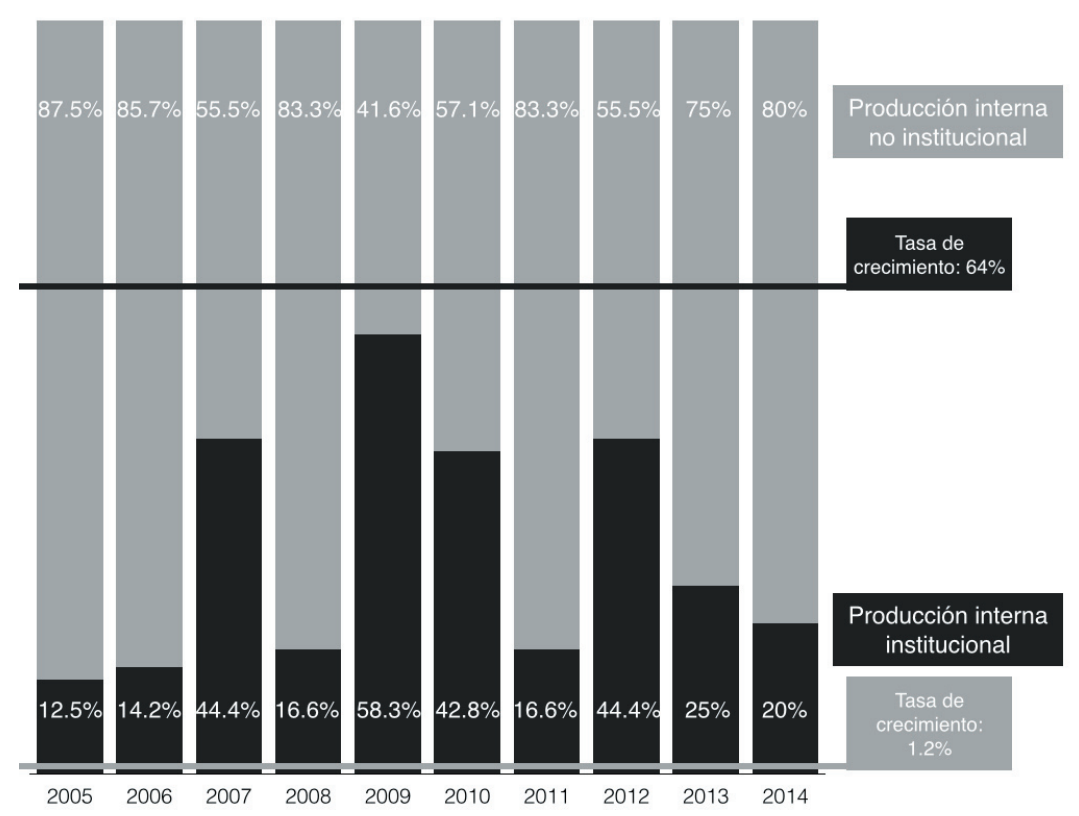

Fuente: SICR, UAEm. Disponible en: <http://www.redalyc.org > . 
Asimismo, dicho peso de la UNAM se aprecia en la distribución por instituciones que más han contribuido en IE, donde dicha institución participa con el 13.3\% del total, seguida del Instituto Politécnico Nacional (IPN), la Universidad Autónoma Metropolitana (UAm), el Colegio de México, A. C. (COlmex) y el Instituto Tecnológico y de Estudios Superiores de Monterrey (ITESM), como se observa en la gráfica 4.

\section{Gráfica 4 \\ Instituciones que contribuyen en la revista, 2005-2014}

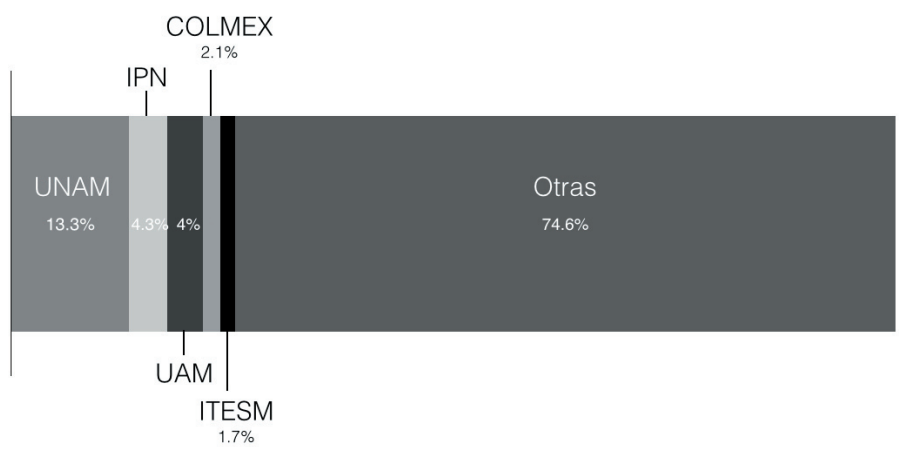

Fuente: SICR, UAEM. Disponible en: <http://www.redalyc.org>.

A su vez, se registran 301 autores que contribuyeron en IE de 2005 a 2014, provenientes tanto de México como del extranjero. En ello se observa que el 86.1\% de los autores tiene sólo un artículo publicado; el 10.3\%, dos; el 2.7\%, tres, y el 0.6\%, cuatro; mientras que sólo hay un autor (Francisco Venegas-Martínez) que publicó una cantidad mayor de artículos (11) y representa el $0.3 \%$. Esto devela que la publicación en cuestión no muestra índices de concentración significativos y que la apertura que se ha logrado al exterior se observa de igual forma en la heterogeneidad de los autores (véase la gráfica 5).

III. Tendencias de colaboración. La colaboración entre investigadores se ha convertido en una estrategia cada vez más recurrente en la forma de generar conocimiento científico, tanto en la ciencia de corriente principal (Plume y Van Weijen, 2014) como en la ciencia emergente. La colaboración es una estrategia que utilizan los investigadores para responder a la demanda de ¿publicar o perecer? que traen consigo los sistemas de evaluación al desempeño en 


\section{Gráfica 5 \\ Artículos por autor, 2005-2014}

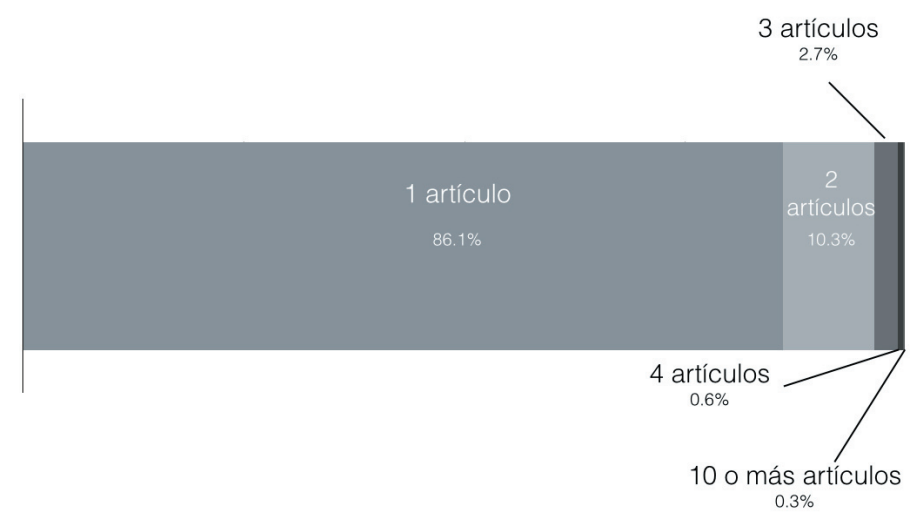

Fuente: SICR, UAEm. Disponible en: <http://www.redalyc.org>.

investigación; además de tratarse también de un modelo de trabajo que desde finales del siglo xx ha ido modificando los cauces de comunicación científica tradicionales y ha dado lugar a una redistribución de los centros de producción científica (De Filippo, Marugán y Sanz, 2014, p. 2), teniendo como soporte la conformación de redes de trabajo formales e informales que por razones diversas optan por el trabajo colegiado (Katz y Martin, 1997, p. 4; Creus y Canals, 2014, p. 3).

El avance de las estrategias colaborativas se observa de igual forma en el acervo iberoamericano que registra redalyc.org, siendo que en 2005 los artículos en coautoría representaron el $42.7 \%$ en las ciencias sociales; el $11.1 \%$ en las humanidades y el $83.5 \%$ en las ciencias naturales y exactas; mientras que en 2014 representaron, en el mismo orden, el $62.4 \%$, el $20.9 \%$ y el $91.6 \%$. Se tiene de tal forma el surgimiento de comunidades policéntricas que se encuentran transformando las estructuras científicas tradicionales a través de una mayor interconexión entre los investigadores (Banerjee, Babini y Aguado, 2015, pp. 25-26).

La revista en cuestión muestra un comportamiento que no es ajeno a las tendencias actuales de colaboración. Se tiene que los artículos colaborativos muestran un comportamiento a la alza, pasando de representar el $52.6 \%$ en la producción de 2005, al 65.0\% en 2014 (crecimiento que se puede observar en la gráfica 6). 


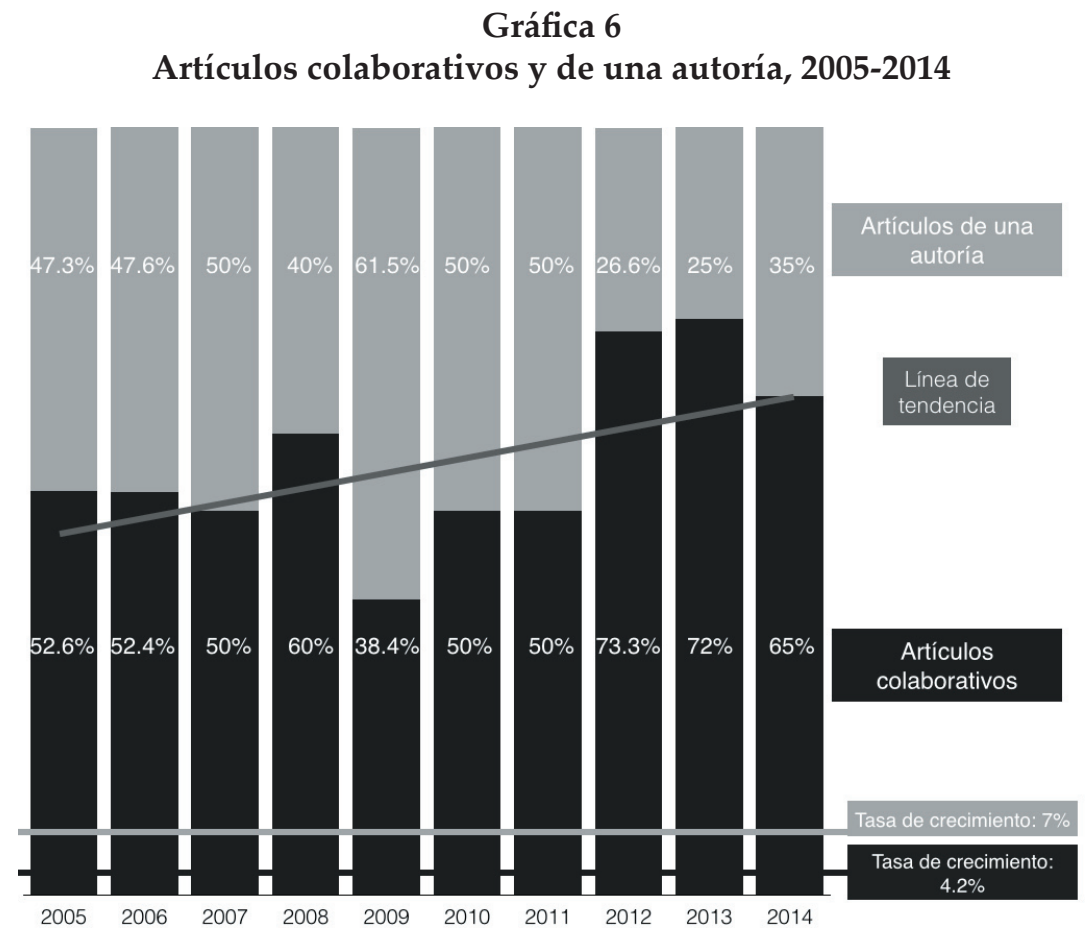

Fuente: SICR, UAEM. Disponible en: <http://www.redalyc.org>.

El incremento de los artículos en coautoría está siendo impulsado por la presencia de la producción externa, especialmente a través de la colaboración entre autores extranjeros, como ya se ha mencionado; aspecto que puede observarse, además, desde la distribución de coautoría interna y externa (véase la gráfica 7), donde esta última tiene un comportamiento más estable en comparación con la coautoría interna, y una tendencia a la alza, sobre todo a partir del 2011, a lo que se suma una tasa de crecimiento más elevada.

En el marco de la coautoría externa se registran 24 países que han participado de forma colegiada, países que en general tienen correspondencia con aquéllos registrados en la producción externa de la revista; se tiene que México ha participado en el 39.6\% de la producción colaborativa, seguido de España, Brasil, Estados Unidos, Argentina, Reino Unido e Italia (véase la gráfica 8).

Por su parte, en la colaboración interna (colaboración entre investigadores adscritos a México) se aprecia que la colaboración entre autores adscritos a la UNAM tiene un comportamiento más estable respecto a la colaboración no 


\section{Gráfica 7}

Coautoría interna y externa, 2005-2014
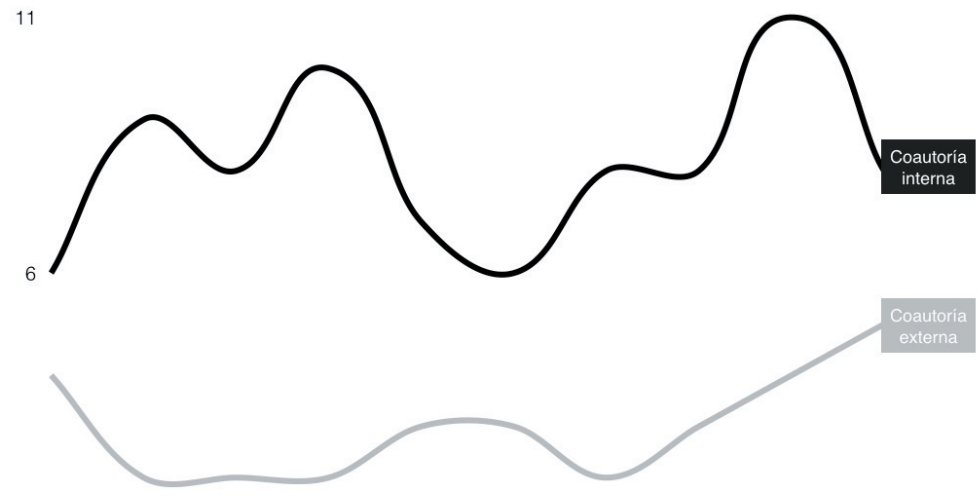

\begin{tabular}{|c|c|c|c|c|c|c|c|c|c|c|}
\hline 2005 & 2006 & 2007 & 2008 & 2009 & 2010 & 2011 & 2012 & 2013 & 2014 & \\
\hline$\%$ & $\%$ & $\%$ & $\%$ & $\%$ & $\%$ & $\%$ & $\%$ & $\%$ & $\%$ & $\begin{array}{c}\text { Tasa de } \\
\text { crecimiento }\end{array}$ \\
\hline $40 \%$ & $18.1 \%$ & $20 \%$ & $16.6 \%$ & $30 \%$ & $33.3 \%$ & $20 \%$ & $27.2 \%$ & $26.6 \%$ & $38.4 \%$ & $8.3 \%$ \\
\hline $60 \%$ & $81.8 \%$ & $80 \%$ & $83.3 \%$ & $70 \%$ & $66.6 \%$ & $80 \%$ & $72.2 \%$ & $73.3 \%$ & $61.5 \%$ & $7 \%$ \\
\hline
\end{tabular}

Fuente: SICR, UAEM. Disponible en: <http://www.redalyc.org>.

\section{Gráfica 8}

Proporción de los países en coautoría, 2005-2014

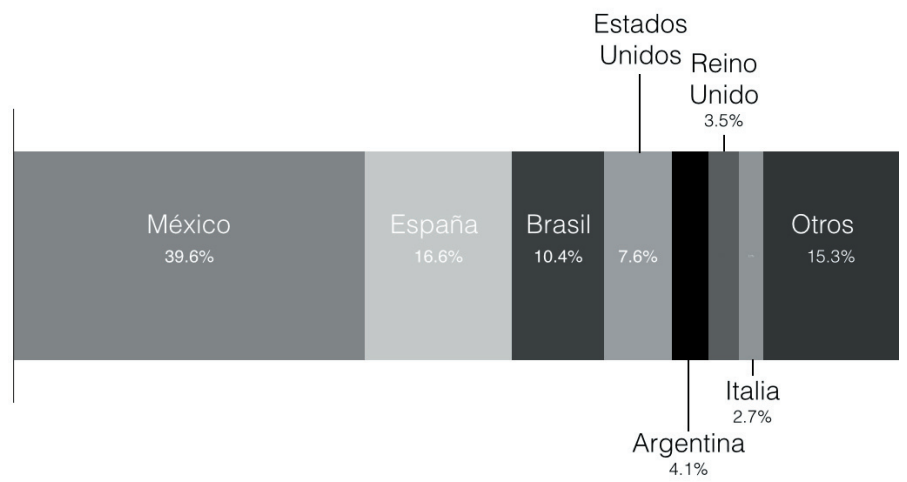

Fuente: SICR, UAEM. Disponible en: <http://www.redalyc.org>. 
institucional, como reflejo de las redes más sólidas de colaboración que han construido los investigadores adscritos a dicha institución, en comparación con aquellas que han tendido en general los investigadores de las instituciones nacionales. Lo que además, como en el caso de la producción interna institucional, refleja prácticas editoriales que tienen una materia pendiente en lo relativo a priorizar y fomentar una colaboración más exógena al interior del país.

\section{Gráfica 9}

\section{Colaboración interna institucional e interna no institucional, 2005-2014}

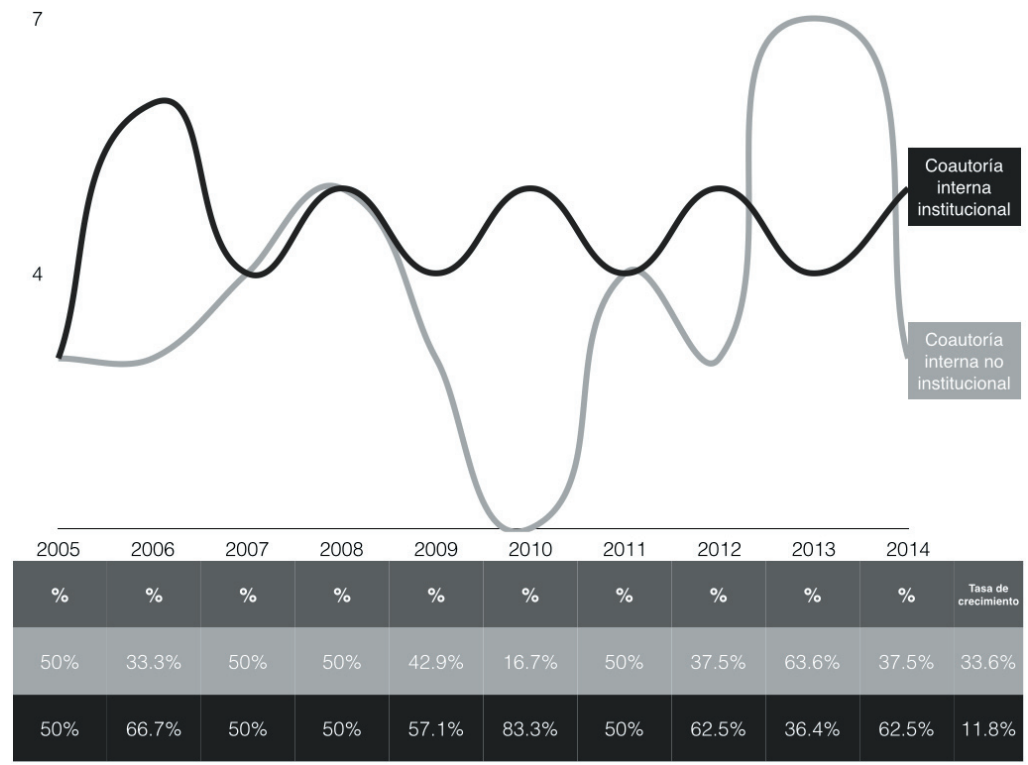

Fuente: sICR, UAEM. Disponible en: <http://www.redalyc.org $>$.

IV. Tendencias de uso. Las descargas por mes que presentan los artículos científicos, en 2013 y 2014, muestran un crecimiento de 16.03\% de enero del 2013 a diciembre del 2014, pese a que el punto más alto de éstas se alcanza en noviembre de 2014, con 6187 descargas mensuales. Cabe señalar que se observa que ambos años suelen cerrar con bajas en la cantidad de descargas, aspecto que impacta negativamente el desempeño de la publicación en términos de uso. Destaca también, como se observa en la gráfica 10, que el comportamiento de éstas supera el promedio que presentan las revistas del área de Economía y Finanzas en redalyc.org, lo que habla del uso privilegiado de IE entre los usuarios, comparando a la revista con las demás publicaciones del área. 


\section{Gráfica 10}

Descargas mensuales de artículos, 2013 y 2014

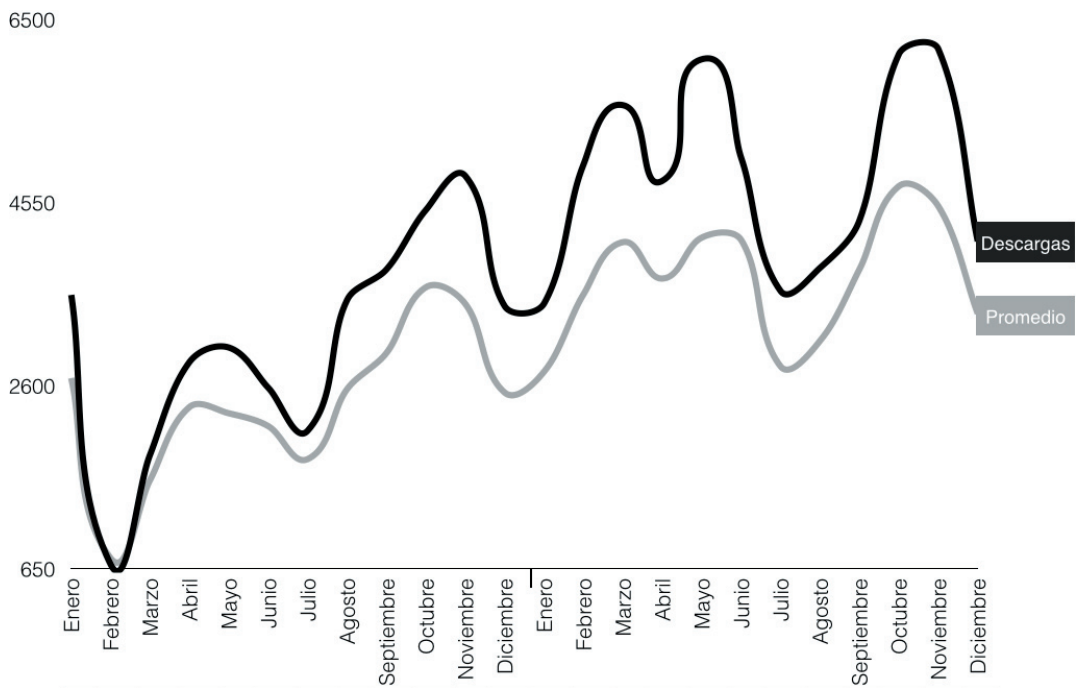

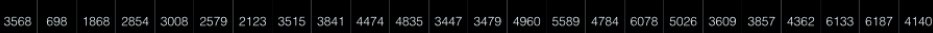

Fuente: sICR, UAEM. Disponible en: <http://www.redalyc.org >.

Asimismo, se observa que la revista ha alcanzado un público internacional, aspecto que se refleja en la distribución de descargas por país, donde sólo el 27.2\% corresponde a descargas realizadas en México (véase la gráfica 11).

\section{Gráfica 11}

Descargas por país, 2013 y 2014

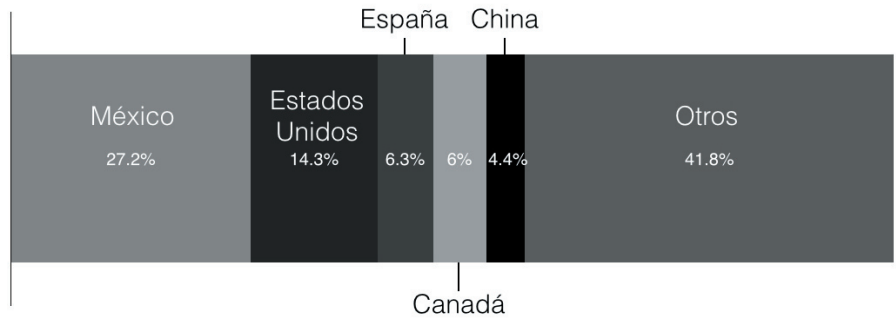

Fuente: SICR, UAEM. Disponible en: <http://www.redalyc.org>. 


\section{Discusión}

En el actual esquema de comunicación científica se busca de los actores una presencia global, es decir, que sean reconocidos y tomados en cuenta en las distintas regiones geográficas y ámbitos de conocimiento. En el caso de las revistas científicas, su impacto y reconocimiento se miden desde su presencia en bases de datos legitimadas, bien como en rankings y citas hechas a los artículos que publican; esto según los estándares en su evaluación. Aunque en todo ello no se tenga un reconocimiento real de su influencia (Bartra, 2015, p. 35) ni de la labor que puedan estar haciendo en sus áreas de conocimiento específicas como canales adecuados de comunicación y debate.

Las revistas científicas han asimilado los principios del sistema de comunicación científica actual, y en función de ello es que desde sus diversas directrices editoriales buscan posicionarse como referentes de consulta y publicación entre los especialistas de sus áreas de conocimiento, centrándose en la búsqueda de visibilidad e internacionalización a partir de varios elementos como son la internacionalidad de los comités científicos y los evaluadores, la internacionalidad de los contenidos (autoría de varios países y colaboración con extranjeros) y la internacionalidad de los usuarios (consultas y/o descargas nacionales y del extranjero) (López, 2010, p. 311).

En este contexto es que el análisis de las publicaciones científicas, es decir, del conocimiento científico que publican, se caracteriza en la actualidad por el hecho de realizarse desde universos de información que no pueden dar cuenta de todo el conocimiento científico que se genera, sino apenas de un fragmento de esto. En el caso que ocupa, dicho fragmento se traduce en la ciencia de corriente principal.

En los análisis bibliométricos se encuentra una herramienta valiosa para trazar un panorama de lo que ocurre en la generación del conocimiento especializado y los canales de circulación empleados, sin embargo, el continuar haciéndolo desde un universo de información fuera de contexto deriva en imágenes distorsionadas de la ciencia escrita que no figura en la corriente principal.

Asimismo, el hecho de orientar las políticas editoriales de las revistas especializadas, las políticas científicas e institucionales, bien como la evaluación del desempeño de la investigación, desde el lugar que pueda ocupar la ciencia escrita en los rankings, es una práctica que debiera reorientarse al contexto regional, donde se comparten problemáticas, agendas de investigación y, en general, un 
pasado histórico que determina el conocimiento que se genera y la forma en que esto se lleva a cabo. En tal sentido, el uso de universos de estudio y esquemas de evaluación propios, además de una gran variedad de mecanismos que pudieran adoptarse en materia científica y editorial, "con el fin de contrarrestar los efectos de las desventajas que la geopolítica del conocimiento nos impone" (Domingues, 2015, p. 8), resultaría para la región un ejercicio de emancipación y una tarea justa para todos los involucrados en el desarrollo científico latinoamericano.

El uso de análisis cienciométricos resulta valioso en el diagnóstico del desempeño del quehacer científico; no obstante, debe recurrirse a universos de información representativa e indicadores pertinentes para cada entidad. En tal sentido es que bases de datos regionales resultan provechosas, como es el caso de redalyc.org, cuya orientación hacia la ciencia regional y las ciencias sociales proporciona no sólo un enfoque novedoso en el análisis del desempeño de Investigación Económica, sino de la ciencia que se publica en revistas iberoamericanas.

Por otra parte, se aprecia en Latinoamérica un esfuerzo en visibilizar el conocimiento científico generado en la región, a través de bases de datos de acceso abierto como SciELO y redalyc.org, bases de datos a las cuales IE se encuentra también indizada; sin embargo, se hace vital reforzar y continuar con los mecanismos de visibilización de la información científica generada al interior de las instituciones regionales (Blanco Olea, 2010, p. 14; Pérez, 2011).

\section{Conclusiones}

IE resulta un referente de internacionalización y visibilidad, desde los tres indicadores propuestos por redalyc.org. En términos de producción, la externa tiene una tendencia a la alza, representando en 2014 el 75.0\% de los artículos que publica IE. A su vez, al observar el análisis pormenorizado de la producción externa, se aprecia que el caso de los autores extranjeros que colaboran entre sí es el más recurrido, seguido de la producción individual de extranjeros y la colaboración entre éstos e investigadores nacionales.

Por su parte, la producción interna se caracteriza por el papel protagónico en determinados periodos de la producción proveniente de la UNAM. Ello resulta en un comportamiento que pudiera considerarse como una señal preventiva para las directrices que pudiera tomar IE en el futuro: cada vez se capta más 
producción de autores extranjeros, que a su vez está siendo impulsada por la colaboración entre investigadores extranjeros; al tiempo que en la producción interna la UNAM ha adquirido un peso importante. ¿Qué decisión cabe tomar? ¿Es esto una situación que requiera atención? Asimismo, sobresale la heterogeneidad que se observa en los autores de IE, donde se aprecia un comportamiento desconcentrado dado que se tiene una participación heterogénea en el $99.7 \%$ de los casos.

En términos de colaboración, se observa que los artículos en coautoría tienen un comportamiento creciente (en 2014 representan el 65.0\% de la producción), el cual está siendo impulsado principalmente por la presencia del exterior en la revista. Resalta que la colaboración entre investigadores de distintos países es la que tiene mejor desempeño, mientras las redes colaborativas de México con el extranjero se encuentran en proceso de consolidación.

Paralelamente, en la coautoría interna se observan redes de colaboración más sólidas entre los investigadores de la UNAM, que entre los investigadores en general de las instituciones nacionales. Tales tendencias en colaboración plantean a IE algunas interrogantes: si la colaboración desplaza al trabajo en solitario y ésta se ve impulsada principalmente por el trabajo en conjunto entre investigadores extranjeros ¿qué papel toca a IE para promover en el país una mayor exogeneidad? ¿En qué medida las prácticas editoriales pudieran promover la construcción de redes colaborativas más sólidas entre los investigadores de alrededor del país y de éstos con investigadores en el extranjero?

Finalmente, en términos de uso, IE experimenta un desenvolvimiento favorable, ya que no sólo supera el promedio de descargas del área de Economía y Finanzas en redalyc.org, sino que se aprecia que sus consultas y descargas se realizan predominantemente en el extranjero ( $72.8 \%$ de los casos).

\section{REFERENCIAS}

Banerjee, I., Babini, D. y Aguado, E., 2015. Tesis a favor de la consolidación del Acceso Abierto como una alternativa de democratización de la ciencia en América Latina. En: P. Suber. Acceso Abierto. México: UAEM.

Bartra, R., 2015. Las revistas cientifíficas en la revolución digital: ¿citas o lectores? Revista Mexicana de Sociología, 77, pp. 33-37. [en línea] Disponible en: $<$ http:/ / www.redalyc.org/articulo.oa?id=32141043003>.

Blanco Olea, F.S., 2010. Análisis bibliométricos de la revista "Educación" de la Pontificia Universidad Católica del Perú (1992-2005). Revista Alexandria, 
4(7), pp. 14-27. [en línea] Disponible en: <http://revistas.pucp.edu.pe/index.php/alexandria/article/view/222>.

Café, L. y Bräscher, M., 2008. Organização da Informaçã e Bibliometria. Encontros Bibli: revista eletrônica de biblioteconomia e ciência da informação, número especial, pp. 54-75. [en línea] Disponible en: <http://www.redalyc.org/ pdf/147/14709806.pdf>.

Carvajal, E. y Matamoros, L., 2012. Análisis bibliométrico de la Revista Costarricense de Psicología, periodo 2001-2011. A propósito de los 20 años de su creación. Revista Costarricense de Psicología, 31(1-2), pp. 1-20. [en línea] Disponible en: <http://rcps-cr.org/wp-content/themes/rcps/descargas/ 2012/0_RCP-Vol.31-No1-2.pdf>.

Creus, A. y Canals, A., 2014. Desarrollo profesional e intercambio de conocimiento en los grandes experimentos científicos. Revista Española de Documentación Cientifica, 37(4), pp. 1-10. Disponible en: <e070. doi: http://dx.doi. org/10.3989/ redc.2014.4.1140>.

De Filippo, D. y Fernández, M.T., 2001. Bibliometría: importancia de los indicadores bibliométricos. $V$ Taller Iberoamericano e Interamericano de Indicadores de Ciencia y Tecnología, Red de Indicadores de Ciencia y Tecnología Iberoamericana y Interamericana (RICYT), Montevideo, Uruguay del 15 al 18 de octubre. [en línea] Disponible en: <http://www.ricyt.org/component/docman/doc_view/113-bibliometria-importancia-de-los-indicadores-biblio metricos? Itemid $=2>$.

De Filippo, D., Marugán, S. y Sanz, E., 2014. Perfil de colaboración científica del sistema español de educación superior. Análisis de las publicaciones en Web of Science (2002-2011). Revista Española de Documentación Cientifica, 37(4), pp. 1-17. [en línea] Disponible en: <http://dx.doi.org/10.3989/ redc.2014.4.1155>.

De Solla Price, D.J., 1986. Little Science, Big Science and Beyond. Estados Unidos: Columbia University Press.

Domingues, J.M. 2015. Proyecciones de la teoría sociológica en América Latina: descripción, análisis y diagnóstico de la modernidad[U5]. Polis, 41. [en línea] Disponible en: <http://polis.revues.org/10968 ; DOI : 10.4000/polis.10968>.

Garfield, E. 2006. The history and meaning of the Journal Impact Factor. The Journal of the American Medical Association, 295(1), pp. 90-93. 
Gómez, A., Ramiro, M.T., Ariza, T., Granados, M.R., 2012. Estudio bibliométrico de Educación XX1. Educación XX1, 15(1), pp. 17-41. [en línea] Disponible en: <http://www.redalyc.org/pdf/706/70621158002.pdf>.

Gordo, Ó., 2014. Evolución de los contenidos de la Revista Catalana d'Ornitologia: un análisis bibliométrico. Revista Catalana d'Ornitologia, 30, pp. 63-85. [en línea] Disponible en: <http://www.ornitologia.org/mm/ file/queoferim/divulgacio/publicacions/rco/30_63_85.pdf > .

Hirsch, J., 2005. An index to quantify an individual's scientific research output. Proceedings of the National Academy of Sciences of the United states of America, 102(46), pp. 16569-16572. [en línea] Disponible en: <http://www.pnas. org/content/102/46/16569.full.pdf>.

Scimago, 2007. SCImago journal and country rank: un nuevo portal, dos nuevos rankings. El profesional de la información, 16(6), pp. 645-646. [en línea] Disponible en: <http://www.elprofesionaldelainformacion.com/contenidos/2007/noviembre/11.pdf $>$.

Horwood, L. y Robertson, S., 2010. Role of bibliometrics in scholarly communication. VALA2010 15th Biennial Conference and Exbibition, Victorian Association for Library Automation (VALA), Melbourne, Australia, 9-11 de febrero. [en línea] Disponible en: <http://www.vala.org.au/vala2010-proceedings/570-vala2010-session-5-horwood $>$.

Katz, J. S. y Martin, B., 1997. What is research collaboration? Research Policy, (26), pp. 1-18.

López, W., 2010. Internacionalización y visibilidad del conocimiento (Editorial). Universitas Psychologica, 9(2), pp. 311-314. [en línea] Disponible en: <http://www.redalyc.org/pdf/647/64716832001.pdf>.

López, E., Vázquez, E. y Sarasola, J. L., 2015. Estudio bibliométrico de PixelBit, Revista de Medios y Educación (2000-2013). Pixel-Bit, Revista de Medios y Educación, 46, pp. 65-85. [en línea] Disponible en: <http://www.redalyc. org/pdf/368/36832959005.pdf>.

Marenco, A. D., 2013. Redes de cooperación científica entre autores e indicadores bibliométricos de una revista de psicología en Colombia (Universitas Psychologica) durante el periodo 2009-2012. Revista Realitas, 1(1), pp. 25-31. [en línea] Disponible en: https://doaj.org/article/ 2aabcfacc0134fe9991ef1ea0f497dad>.

Morales Gaitán, K.; Aguado López, E. (2010). La legitimación de la Ciencia Social en las bases de datos científicas más importantes para América 
Latina. Latinoamérica. Revista de Estudios Latinoamericanos, 51, pp. 159-188. [en línea] Disponible en: <http://www.scielo.org.mx/.0.php?script=sci_ arttext\&pid=S1665-85742010000200008\&lng=es\&tlng=es $>$.

Moreno, D. y Urzúa, C., 2015. Análisis bibliométrico de los trabajos libres de neurocirugía presentados en los congresos nacionales de la Sociedad Chilena de Neurocirugía entre los años 2010 y 2013. Revista Chilena de Neurocirugia, 1(41), pp. 72-75. [en línea] Disponible en: <http://www.aulamedic. $\mathrm{com} /$ revistas/neurocirugia/2015/n41v1/10-Moreno.pdf $>$.

Pérez, J., 2011. Las revistas científicas y su visibilidad (Editorial). Sapiens. Revista Universitaria de Investigación, 12(1). [en línea] Disponible en: <http://www. redalyc.org/articulo.oa?id $=41030367001>$.

Plume, A. y Van Weijen, D., 2014. Publish or perish? The rise of the fractional autor. Research Trends, 38. [en línea] Disponible en: <http://www.researchtrends.com/issue-38-september-2014/publish-or-perish-the-rise-of-thefractional-author $/>$.

Romaní, F., Huamaní, Ch. y González, G., 2011. Estudios bibliométricos como línea de investigación en las Ciencias Biomédicas: una aproximación para el pregrado. Ciencia e Investigación Médica Estudiantil Latinoamericana, 16(1), pp. 52-62. [en línea] Disponible en: <http://www.imbiomed.com.mx/1/1/articulos.php?id_ejemplar=8634\&id_revista $=126>$.

Sánchez, A., Carrillo, O. y Garrido, P., 2015. Análisis bibliométrico de la Revista Mexicana de Sociología basado en indicadores de citación. Revista Mexicana de Sociología, 77, pp. 45-70. [en línea] Disponible en: <http://www.redalyc. org $/$ articulo.oa?id=32141043005>.

Spinak, E., 1996. Los análisis cuantitativos de la literatura científica y su validez para juzgar la producción latinoamericana. Boletín de la Oficina Sanitaria Panamericana, 120(2), pp. 139-147. [en línea] Disponible en: <http://www. garfield.library.upenn.edu/papers/pahov120(2)p146y1996.pdf $>$.

Spinak, E., 1998. Indicadores cienciométricos. Ciencia da Informaçao, 27(2), pp. 141-148. [en línea] Disponible en: <http://dx.doi.org/10.1590/S010019651998000200006>.

Zamorano, E., 2012. (Editorial). Revistas universitarias y la parábola del salmón. Theoria, 21(1), pp. 5-7. [en línea] Disponible en: <http://www.redalyc. org:9081/articulo.oa?id $=2993176900>$. 